6. Hofmann, E., Havens, B., Hoppenbrouwers, T., Geidel, S., and Hodgman, J.: Long-term continuous monitoring of multiple physiological parameters in newborn and young infants: A procedural manual (Submitted for publication; manuscript available on request.)

7. Kero, P.: Heart rate variation in infants with the respiratory distress syndrome. Acta Pediat. Scand., Suppl. 250 (1974)

8. Lewis, M., Bartels, B., and Goldberg, S.: State as a determinant of infants' heart rate response to stimulation. Science, 155: 486 (1967).

9. Lewis, M., Wilson, C. D., Ban, P., and Baumel, M. H.: An exploratory study of resting cardiac rate and variability from the last trimester of prenatal life through the first year of postnatal life. Child Develop., 41: 799 (1970).

10. Lipton, E., Steinschneider, A., and Richmond, J.: Autonomic function in the neonate. VII. Maturational changes in cardiac control. Child Develop., 37(1):1 (1966).

11. Prechtl, H. F. R., Weinmann, H., and Akiyama, Y.: Organization of physiological parameters in normal and neurologically abnormal infants. Neuropediatrie, 1: 101 (1969).

12. Roffwarg, H. P., Muzio, J. N., and Dement, W. C.: Ontogenetic development of the human sleep-dream cycle. Science, 152: 604 (1966).

13. Tarlo, P. A., Valimaki, I., and Rautaharju, P. M.: Quantitative computer analysis of cardiac and respiratory activity in newborn infants. J. Appl. Physiol., 3/(1): 70 (197I).

14. Urbach, J. R., Phuvichit, B., Zweizig, H., Millkan, E., Carrington, E. R., Loveland, M., Williams, J. M., Duncan, A. M., Farrell, S. L., Simons, P. O., and Spurgeon, I. L.: Instantaneous heart-rate patterns in newborn infants. Amer. J. Obstet. Gynecol., 93: 965 (1965).

15. Valimaki, I.: Heart-rate variation in full-term newborn infants. Biol. Neonate, 18: 129 (1971)

16. Valimaki, I., Rautaharju, P. M., Roy, S. B., and Scott, K. E.: Heart rate patterns in healthy term and premature infants and in respiratory distress syndrome. Eur. J. Cardiol., I(4): 411 (1974).

17. Valimaki, I., and Tarlo, P. A.: Heart rate patterns and apnea in newborn infants. Amer. J. Obstet. Gynecol., 110(3): 343 (1971).

18. Vallbona, C., Desmond, M. M., Rudolf, A. J., Papp, L. F., Franklin, R. R., and Rush, J. B.: Cardiodynamic studies in the newborn. II. Regulation of the heart rate. Biol. Neonate, 5: 159 (1963).

19. Vranekovic, G., Hock, E., Isaac, P., and Cordero, L.: Heart rate variability and cardiac response to an auditory stimulus. Biol. Neonate, 24: 66 (1974).

20. Watanabe, K., Iwase, K., and Hara, K.: Heart rate variability during sleep and wakefulness in low birthweight infants. Biol. Neonate, 22: 87 (1973).

21. Grass Instruments Co., Quincy, Mass.

22. Gould Inc., Instrument Systems Division, Los Angeles, Calif.

23. Beckman Instruments, Palo Alto, Calif.

24. Honeywell, Test Instruments Division, Denver, Colo.

25. Systron Donner Corp., Concord, Calif.

26. Digital Equipment Corp., Maynard, Mass.

27. Houston Instruments, Bellaire, Texas.

28. We would like to thank Dr. E. Gocka for his statistical help in these studies. D. Bannett, S. Geidel, B. Havens, D. Hockin, D. Kelly, and J. R. Mason also made valuable contributions to this study. Computational support was received from the Biomedical Engineering and Computing Center at the Sepulveda Veterans Administration Hospital.

29. This research was supported by the Veterans Administration and by the National Institute of Child Health and Human Development Contracts nos. N01HD-2-2777 and HD4-2810.

30. Requests for reprints should be addressed to: R. M. Harper, Ph.D., Department of Anatomy, University of California, Los Angeles, Calif. 90024 (USA).

31. Accepted for publication May 25, 1976.

\title{
Effect of Undernutrition and Amino Acid Deficiency on the Timing of Puberty in Rats
}

\author{
A. R. GLASS, R. HARRISON, AND R. S. SWERDLOFF ${ }^{121}$ \\ Harbor General Hospital Campus, UCLA School of Medicine, Torrance, California, USA
}

Extract

Sexual maturation was examined in underfed or amino acid-deficient rats. We have demonstrated a highly significant negative linear relationship ( $r=-0.80, P<0.001$ ) between the age at puberty and the growth rate in rats under conditions of food restriction. The weight at puberty in animals growing at different rates because of undernutrition was not constant but behaved as a quadratic function of growth rate, as predicted from the assumption that growth rate was an independent variable. Growth rate is therefore more important than arrival at a particular fixed weight in determining the timing of puberty. Feeding of low valine diets resulted in delayed sexual maturation. Both the weight at vaginal opening $(182 \pm 5.9 \mathrm{~g})$ and the weight at first estrus $(187 \pm 6.1 \mathrm{~g})$ were significantly greater in the valine-deficient group when compared with growthmatched control $(139 \pm 10.7 \mathrm{~g}$ and $161 \pm 9.3 \mathrm{~g}$, respectively, $P<$ 0.05). The valine-deficient group also had significantly later vaginal opening (98.8 $\pm \mathbf{4 . 7}$ days) than growth-matched controls $(76.6 \pm$ 6.6 days, $P<0.02$ ). Valine deficiency seemed to have a specific effect on the hypothalamic-pituitary-gonadal axis since puberty in valine-deficient animals was delayed more than could be accounted for by impairment of growth.
Speculation

In contrast with previous suggestions in animals and man, we have shown that in rats the weight at puberty is not constant under conditions of underfeeding or valine deficiency. Growth rate seems to be more important than arrival at a particular fixed weight in determining the onset of puberty, possibly through a linkage between growth rate and hormone production rates. Valine deficiency may cause delayed puberty by altering central nervous system neurotransmitters.

The relationship between somatic growth and sexual maturation has been a topic of interest to clinicians and researchers for many years. Further excitement was generated in 1970 by the proposal of Frisch and Revelle that menarche in girls tends to occur at a critical constant body weight and that this phenomenon is important in understanding the hormonal basis of puberty $(3,4)$. This proposal was inspired in part by evidence suggesting that puberty in animals tended to occur at a constant body size. Subsequently, Frisch has modified her hypothesis to state that menarche in girls tends to occur at a critical constant body 
composition $(2,5)$. In recent years, however, objections have been raised to both the "critical weight" and "critical body composition" theories $(1,6,7)$. In view of this controversy, we have re-examined the original finding of constant body size at puberty in animals by observing sexual maturation in underfed or amino acid-deficient rats. These experiments also provided us with the opportunity to see if the process of growth could be dissociated from sexual maturation by dietary manipulation.

\section{MATERIALS AND METHODS}

Synthetic amino acid diets were obtained in either powdered or pelleted form (15). The components of the two diets (control and low valine) used in the experiments are shown in Table 1. The compositon of these diets was based on work done previously on the use of synthetic diets for rats (11-13). Moreover, it was shown in a preliminary experiment that feeding of the control diet ad libitum to rats resulted in normal growth and sexual maturation.

Twenty-one-day-old female Wistar rats (16) were sorted according to weight and then randomized into groups of eight, each group having the same mean weight. All animals were housed in individual cages with a 14/10 light-dark cycle and provided free access to water. One group of eight animals was fed the control diet ad libitum (group $C l$ ) while another group (group $V$ ) was fed the low valine diet ad libitum. A third group (group C7) was pair-fed the control diet to match the growth of the group fed the low valine diet. Several additional groups (groups $C 2-C 6$ ) were fed the control diet in predetermined amounts ranging from 5-15 g/day.

All animals were weighed and examined daily for vaginal opening; after vaginal opening, daily vaginal smears were done. The occurrence of first estrus was defined by the appearance of the first cornified vaginal smear that was both preceded and followed by a diestrus smear. The growth rate for each animal was defined as the mean weight gain per day from age 30 to age 60 days, and the inean growth rate for each group calculated as the average of the individual growth rates for members of that group. These ages were chosen to provide the broadest measure of growth applicable to all groups, some of whom were killed shortly after age 60 days. Weight changes below age 30 days were due in part to the effects of

Table 1. Composition of experimental diets (grams per $100 \mathrm{~g}$ diet)

\begin{tabular}{ccc}
\hline Variable components & Control diet & Low valine diet \\
\hline Val & 0.70 & 0.28 \\
Gly & 0.82 & 1.24 \\
\hline
\end{tabular}

Components identical in control and low valine diet

\begin{tabular}{lclc}
\hline Met & 0.60 & Arg-HCl & 0.50 \\
Ala & 0.23 & Asp & 0.23 \\
Asn & 0.40 & Gly & 3.29 \\
Pro & 0.23 & Cys & 0.23 \\
Cys & 0.23 & Ser & 0.23 \\
His-HCl & 0.38 & Ile & 0.69 \\
Leu & 0.86 & Lys-HCl & 1.40 \\
Phe & 0.90 & Thr & 0.64 \\
Trp & 0.14 & & \\
Corn oil & 15.0 & Dextrin & 37.0 \\
Sucrose & 30.0 & Salt mix R H & 5.0 \\
Vitamin mix $^{2}$ & 0.4 & L-Choline & 0.1 \\
\hline
\end{tabular}

${ }^{1}$ Purchased from ICN Pharmaceuticals (15) with composition previously described (13).

${ }^{2}$ This supplies the following quantities per 100-g diet (in milligrams): vitamin A, 1.80; vitamin D, $0.10 ; \alpha$-tocopherol, 2.00; ascorbic acid, 18.00; inositol, 2.00; choline chloride, 30.00; menadione, $0.95 ; p$-aminobenzoic acid, 2.00; niacin, 1.80; riboflavin, 0.40 ; pyridoxin- $\mathrm{HCl}, 0.40$; calcium pantothenate, 1.20; biotin, 0.008 ; folic acid, 0.036; vitamin $\mathrm{B}_{12}, 0.00054$. adjustment to individual housing. Statistical comparisons were done with the unpaired $t$-test unless otherwise specified, and all data are reported as mean \pm SEM

\section{RESULTS}

\section{GROWTH RATES}

The growth curves of groups $C l-C 7$ and group $V$ are shown in Figure 1.

\section{AGE AT PUBERTY}

The ages at vaginal opening for each of the groups $\mathrm{Cl}-\mathrm{C} 7$ are plotted in Figure 2 against the corresponding mean group growth rates on the abscissa. The ages at first estrus for these same groups are similarly plotted in Figure 3. Under the experimental condition of food restriction, the food intake and hence the corresponding growth rate was clearly the independent variable. Application of linear regression showed that both the age at vaginal opening and the age at first estrus were highly significant negative linear

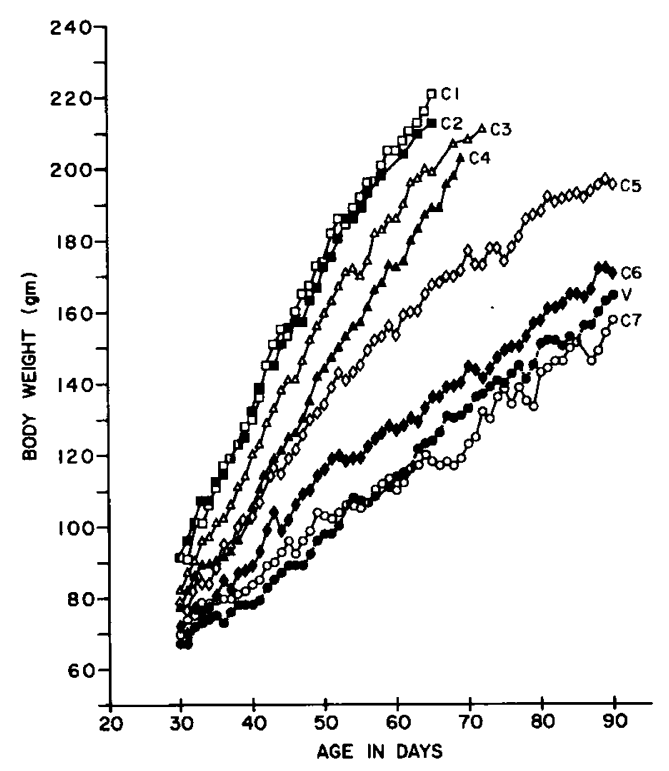

Fig. 1. Growth curves for groups $C 1-C 7$ (fed reduced amounts of control diet) and group $V$ (valine deficient). Each point is the mean body weight of all members of the group.

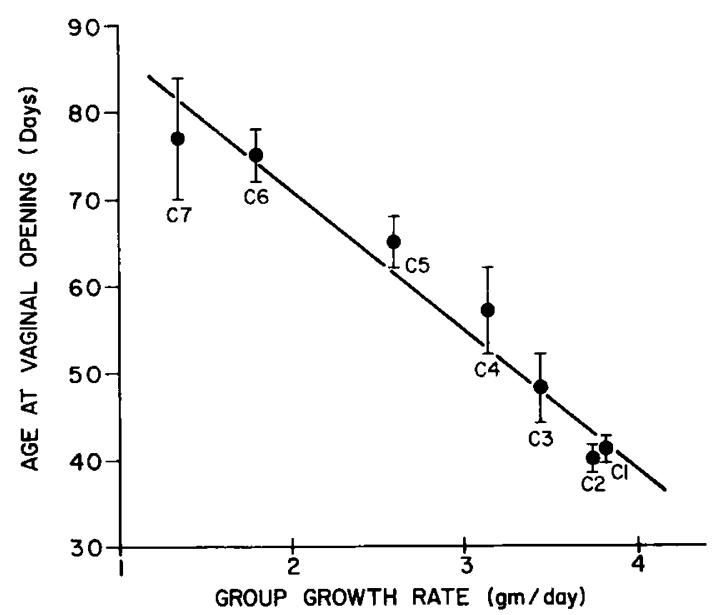

Fig. 2. Ages at vaginal opening for groups $\mathrm{Cl}-\mathrm{C} 7$, plotted as mean \pm SEM. The mean group growth rate (as defined in Methods) is shown on the abscissa. Least squares line is $\mathrm{y}=-15.6 \mathrm{x}+102(r=-0.80, P<0.001)$. 